ставляют чувствовать себя «настоящим художником», позволяя ему быстро создавать профессионально выглядящую работу путем выбора ряда опций из имеющегося программного меню. Примерами такого «авторства по выбору» являются веб-сайты, которые позволяют пользователям быстро создавать мультимедийную открытку, короткий фильм, выбирая из меню изображения и звуки. Ролан Барт определил культурный текст как «ткань цитат из бесчисленных культурных кодов». В производственной среде, управляемой программным обеспечением, эти цитаты приходят не только из воспоминаний создателей о том, что они видели раньше, читали и слышали, но и непосредственно из баз данных медиа.

Сотрудничество между автором и программным обеспечением. При использовании программного обеспечения в творческом процессе автор устанавливает некоторые общие правила, но он не имеет контроля над конкретными деталями работы - они возникают в результате взаимодействия правил. В более общем смысле мы можем сказать, что все авторство, использующее электронные и компьютерные инструменты, является сотрудничеством между автором и этими инструментами, которые делают возможными только определенные творческие операции. Манович подмечает, что безусловно эти инструменты разработаны людьми, поэтому, если сказать точнее, автор, который использует электронные / программные инструменты, участвует в соавторстве с разработчиками программного обеспечения.

Интересно, что проведенный опрос субъектов DIY в области производства зинов (самоизданных публикаций) выявил, что большинство не видят принципиальной разницы между ручным и цифровым DIY. «Для меня DIY это самостоятельная работа с применением всех подручных средств, инициатива, которая возникает не из-за денег. У меня нет команды, которой я плачу деньги за работу, все, кто принимают участие, - делают это по фану, подхватывают идею и вносят свой вклад» (Аня Интерес, «Я-так-вижу-ЗИН).

Таким образом, с одной стороны, мы видим засилье бесконечно копируемого и воспроизводимого контента по коммерчески успешным шаблонам, где вопрос личного участия, креативной составляющей процесса ставится под сомнение. С другой же - цифровая среда изменяет и размывает устоявшиеся, привычные нам границы авторства, доступностью и легкостью интерфейса побуждая все больше вовлекаться к производству творческого продукта.

DOI: $10.17223 / 22220836 / 36 / 37$

\title{
С.В. Горбунова
}

\section{САМ СЕБЕ ЭКОЛОГ: КАК ОСОЗНАННОЕ ПОТРЕБЛЕНИЕ ПРЕВРАЩАЕТСЯ В МОДНЫЙ МИФ ${ }^{1}$}

В современном обществе все сильнее набирает обороты экологическая активность различного рода и формата. Все больше людей - будь то пенсионеры или подростки - сортируют бытовые отходы, выезжают сажать деревья, отказываются от пакета в супермаркете. Возникают всевозможные экологи-

\footnotetext{
${ }^{1}$ Исследование выполнено за счет гранта Российского научного фонда (проект № 19-18-00237).
} 
ческие сообщества с амбициозными названиями типа «Чистая планета» (несколько одноименных сообществ в социальных сетях с количеством подписчиков меньше сотни), «Тайга. Экология головного мозга» («тайга» - при условии, что оффлайн этого сообщества находится в Москве), «Новая ЭРА» («эра» - в рамках отдельно взятого университета) и не совсем понятными широким массам ассоциативными названиями - «Van Gog» (где по задумке автора «Gog» - это «God», но почему - не объясняется). Проводятся акции от флешмобов до пикетов и митингов. Экологическим объявляется все: от продуктов питания и одежды до... танцев. Более того, понятием «экологичный» синонимически подменяются понятия «грамотный» (экологичная речь), «здоровый» (экологичный распорядок дня), не говоря уже о более «тонких» подменах в рамках тематической группы: расхожее выражение «у нас плохая экология», в котором под экологией подразумевается состояние окружающей среды.

С одной стороны, стоит признать, что волнения общественности в области экологии - хороший знак. С другой - интерес к экологии и проблемам окружающей среды становится модным веянием, под влиянием которого формируются превратные представления, «мифы» и, как следствие, ложные прогнозы и экологически неправильное поведение. Подлинное экологическое просвещение, необходимое для формирования экологической культуры, подменяется модой, что, помимо всего прочего, компрометирует экологовпрофессионалов и способствует негативной реакции общества на действия экоактивистов.

Не претендуя на всесторонний анализ, рассмотрим причины возникновения, популяризации и массовизации экоориентированности и связанные с этим риски.

Во-первых, следует отметить, что на сегодняшний день осознанное потребление в России является своего рода контркультурой. Так, по данным различных организаций, раздельный сбор практикуют от 6-8 до 28-30\% населения страны. Значительное расхождение данных связано с тем, что разные структуры (общественные организации, операторы по обращению с твердыми коммунальными отходами, перерабатывающие компании, власть) рассматривают ситуацию в зависимости от своих интересов и выгоды. Но точно можно утверждать, что раздельный сбор бытовых отходов практикует меньшинство населения. При этом активная часть менышинства борется за свои права всеми доступными способами. В качестве примера можно привести актуальную для Томска ситуацию: местная коммерческая компания «Чистый мир» и аналогичный новосибирский оператор «Планета без мусора», осуществлявшие до настоящего времени сбор и досортировку вторсырья, стали объектом конкурентной борьбы со стороны Спецавтохозяйства, назначенного региональным оператором (вплоть до самовольного перемещения и удаления имущества этих компаний - сеток для сбора вторсырья). В связи с чем местное экологическое сообщество проводит кампанию по поддержке данных организаций (ведет информационную работу, организует акции, готовит петиции и обращения в органы власти).

Но, как в случае с любой контркультурой, существует определенный процент тех, кого привлекает в ряды активистов именно составляющая «контр-», так как быть в меньшинстве, поддерживать интересы тех, кто в оп- 
позиции, модно. А когда острота ситуации спадает, количество «последователей» уменьшается.

Другая распространенная тенденция, связанная непосредственно с «вещной» модой, - отказ от «неэкологичных» продуктов массового производства. Это стимулирует поиск альтернатив как промышленного исполнения (например, стакан для кофе с собой многоразового использования), так и изготовление hand-made продукции (шоппер - многоразовая сумка, фруктовка многоразовый пакет для упаковки фруктов, овощей, хлебобулочных изделий и т.д.). В данном случае проблема заключается в том, что такие действия практикуют как сознательные представители экодвижения, так и приверженцы модных трендов, оставаясь при этом экологически равнодушными. Воспринимаемые как часть сообщества, они дискредитируют его своей некомпетентностью и пассивностью.

Казалось бы, такая мода затратна и не всегда удобна: необходимо носить с собой многоразовый стакан, шоппер, самостоятельно шить и регулярно стирать фруктовки; не каждый готов вставать на пробежку, а во время плоггинга нужно еще и собирать мусор. Тем не менее число «случайных попутчиков» экодвижения не уменьшается.

Еще один популярный в последнее время экоориентированный тренд высадка деревьев. Подобные акции используются, например, в качестве замены экологически вредному запуску гелиевых шаров на различных мероприятиях (выпускные, бизнес-форумы, дни рождения компаний и т.д.). Но сформируют ли высаженные деревья систему (биоценоз), смогут ли встроиться в существующие экосистемы, да и выживут ли вообще - мало кого интересует. Между тем за популярным для таких целей кедром необходимо ухаживать первые 26 лет жизни, иначе высадка окажется бессмысленной.

Следует отметить, что действия экоактивистов, направленные на снижение объемов производства и переход к осознанному потреблению, во многом похожи на советские бытовые практики: сбор макулатуры, металлолома, стеклотары, покупка разливных напитков в свою тару, использование многоразовых авосек, сеток, самошитых мешочков (с появлением полиэтиленовых пакетов практика многоразового использования распространялась и на них: пакеты мыли, сушили и использовали повторно). Говоря о советском опыте, важно иметь в виду, что в условиях, когда страна не испытывала дефицита природных ресурсов, рациональное использование их было повседневной нормой - не модным трендом и не панацеей от глобальных экологических проблем, а неотъемлемой частью бытовой культуры, культуры потребления. Современная мода кажется похожей на советские практики и частично удовлетворяет экологические запросы тех, кто застал это время. Однако экологическая культура в условиях современности, к сожалению, не сформирована.

В качестве еще одной проэкологичной тенденции, уходящей корнями в советское прошлое, когда все необходимое ремонтировалось, а многое и создавалось по принципу DIY («do it yourself»), можно выделить самостоятельное обустройство окружающей территории - начиная от локальных субботников по сбору мусора около дома и заканчивая сооружением и ремонтом объектов городской среды (например, уличной мебели для детских площадок и мест отдыха). Актуальные примеры такой деятельности - инициатива подростков сообщества субкультуры панков в Челябинске по ремонту детской 
горки на дворовой игровой площадке и обустройство территории Университетского озера и системы питающих его родников по личной инициативе гидролога А.Д. Назарова и помогающих ему волонтеров в Томске. Однако такая деятельность зачастую не находит поддержки и благодарности у тех, кто должен заниматься подобными вещами в силу профессиональных и должностных обязанностей. Более того, самодеятельные инициативы дают повод «расслабиться» коммунальным службам, административным структурам и другим ответственным организациям, которые перестают решать свои непосредственные задачи и игнорируют сообщения населения о существующих проблемах, а то и вовсе препятствуют энтузиастам. Так, например, по факту самостоятельного ремонта моста жителями пос. Чкаловский в Свердловской области следственный комитет организовал проверку, а при обустройстве томских родников в 2016 г. уличная мебель была украдена, а сооружения неоднократно ломались вандалами, так как эта территория никем не охраняется.

Перечисленные практики объединяет общая черта: все они удовлетворяют нашу потребность в сопричастности и самоактуализации, вызывая тем самым позитивные чувства и эмоции, что и создает основу для их «мифологизации». Но станет ли объективно лучше от того, что мы подпишем очередное обращение или поучаствуем в митинге, сдадим больше макулатуры или пластика, будем покупать кофе в свою тару или носить с собой сумку для продуктов, бросимся сажать деревья и ремонтировать лавочки?

Казалось бы, неважно, что движет человеком, если он своими действиями поддерживает хорошее начинание. Однако здесь следует вспомнить, что экология - это наука. И как любая наука она имеет свой предмет, методы, подходы. Предмет экологии - природные и антропогенные системы и существующие в рамках этих систем связи. Если все внимание уделять одним и тем же проблемным местам, игнорируя при этом другие компоненты систем и их связи, эффект может нивелироваться или даже оказаться негативным. Таким образом, без понимания общей картины происходящего, без рефлексии, зачем совершается то или иное действие, невозможно оценить масштаб проблемы, правильно спрогнозировать результат и выбрать эффективную стратегию для ее решения. Поэтому позитивные, на первый взгляд экоориентированные тенденции могут быть опасны для окружающей среды и человека. Изменить ситуацию и направить самодеятельные инициативы в конструктивное русло может повышение экологической грамотности населения и формирование экологической культуры как необходимого условия развития цивилизации. 